R.L. Knill MD FRCP(C), P.Y.K, Lok RRT, J.P. Strupat RRT, A.M. Lam MD FRCP(C)

\title{
Blood solubility of isoflurane measured by a multiple gas phase equilibration technique
}

Using a multiple gas phase equilibration technique, we determined the solubility of isoflurane in arterial blood at $37^{\circ} \mathrm{C}$ obtained from patients anaesthetized with isoflurane. Goodness of fit of individual sets of data to a predicted decline of isoflurane concentration in succes. sive equilibrated gas phases and reproducibility of results indicate that the analytical technique was acceptably accurate. In blood samples taken from twenty-three patients undergoing minor surgical procedures, the bloodigas partition coefficient of isofiurane was $1.20 \pm$ 0.08 (mean \pm S.D.). Individual values were not detectably related to absolute tension of isoflurane, preoperative haemoglobin concentration nor patient age. In samples taken from twenty neurosurgical patients, the blood'gas partition coefficient was slightly less, $1.14 \pm 0.09$ (p< 0.05 ), a difference we attribute to the effect of previously infused mannitol. In vitro, blood solubility of isoflurane was decreased by haemodilution with normal saline, mannitol 20 per cent or plasma, was increased by hypothermia $\left(30^{\circ} \mathrm{C}\right)$ and was decreased by hyperthermia $\left(40^{\circ} \mathrm{C}\right)$. We conclude that the solubility of isoflurane in human blood is approximately half that of halothane.

\section{Key words}

SOLURILITY: partition coefficients; ANAESiTHETICS, VOLATILE: isoflurane.

From the Department of Anaesthesia, University Hospital and University of Western Ontario, London, Canada.

Address correspondence to: Dr. R.L. Knill, Department of Anaesthesia, University Hospital, P.O. Box 5339, Postal Station A, London, Ontario N6A 5A5.

Supported in part by a Grant-in-Aid from Ohio Medical Products.
The blood/gas partition coefficient of isoflurane in human blood was found to be $1.43 \pm 0.02$ by Cromwell et al. ${ }^{1}$ and $1.20 \pm 0.05$ by Munson et $a .^{2}$ (means \pm S.E.M.). Both sets of values were determined in experiments in which samples of blood from unanaesthetized volunteers were exposed to isoflurane vapour in vitro. The concentration of isoflurane used in Munson's study was 0.6 per cent - i.e. less than the concentration that would be required for anaesthesia with isoflurane alone. The concentration used in Cromwell's study was not reported.

The purpose of our study was to measure isoflurane solubility in arterial blood exposed to isoflurane in anaesthetizing concentrations in vivo. We obtained samples of arterial blood from a series of patients who were anaesthetized with isoflurane. Adapting a method used in analytical chemistry, ${ }^{3}$ we determined the blood/gas partition coefficient in each sample from the concentrations of isoflurane observed in a series of gas phases which were equilibrated successively with the sample.

\section{Methods}

Duplicate $10 \mathrm{ml}$ samples of arterial blood were taken from each of 43 patients anaesthetized with isoflurane or isoflurane-nitrous oxide $50-70$ per cent. Samples were taken by arterial puncture, with the patient's consent, or through an arterial cannula in place for clinical purposes. At the time of sampling, inhalational anaesthesia had been maintained for at least 30 minutes with inspired isoflurane concentrations set according to clinical requirements. The patients were undergoing gynaecological, orthopaedic, dental or ENT surgery of a minor nature, or major neurosurgical procedures.

Each sample of blood was collected anaerobi- 
cally via a three-way metal stopcock into a calibrated gas-tight glass syringe which had been pre-wetted with heparin. The volume of the deadspace of the syringe and stopcock were known. Samples were sealed immediately and placed in ice until analysis, which was commenced within six hours.

In the laboratory, a volume of humidified air somewhat less than the volume of blood was added to the sample syringe and the syringe was transferred to a shaking water bath maintained at $37^{\circ} \mathrm{C}$ (range $\pm 0.1^{\circ} \mathrm{C}$ ). The volume of air added was selected so that when heated and equilibrated with the blood, the total gas phase volume would become identical to or just slightly less than the volume of blood. After 20 minutes of equilibration, an additional volume of air was added carefully to the syringe, if necessary, to make the total volume of gas, once heated and equilibrated, precisely identical with that of the blood. Gas and blood were then re-equilibrated for 20 minutes and a check made to ensure that the gas and blood volumes were equal. A portion of the gas phase was flushed into the gas sampling loop of a Hewlett Packard \#5730A gas chromatograph, which was fitted with a flame ionization detector. The sample syringe was disconnected and residual gas completely expelled. Additions and removal of gas to and from the syringe were made during momentary openings of the stopcock while the syringe was held vertical with its Luer tip up.

The blood sample was equilibrated with humidified air a second, third and fourth time, in the manner described above. The three additional equilibrated gas phases were also flushed into the gas chromatograph.

The chromatograph column was packed with Carbopack "B" coated with SE-300.8 per cent. For analysis of gas phases, the column was maintained at $170^{\circ} \mathrm{C}$, the injection port at $200^{\circ} \mathrm{C}$ and the detector at $250^{\circ} \mathrm{C}$. Chromatogram peak heights were calibrated each testing day with vapour concentration standards we prepared in our laboratory by injecting precisely measured amounts of isoflurane liquid into a closed chamber of known volume, temperature and pressure. Standard curves relating peak height to isoflurane vapour concentration were linear between 0.2 and 2.0 per cent and passed through the origin. Calibrations were unaffected by $\mathrm{N}_{2} \mathrm{O} 50-70$ per cent in the calibrating mixture.

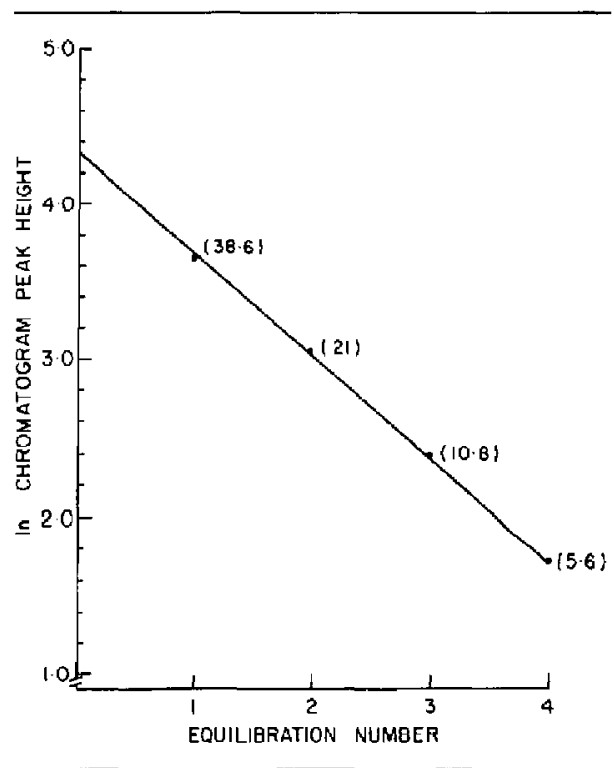

FIGURE 1 Deternination of the blood/gas partition coeffcient and the blood tension of a volatile anaesthetic by multiple gas phase equilibration. Points are the natural logarithms of chromatogram peak heights representing isoflurane detected in successive gas samples equilibrated with a sample of blood. Bracketed values are actual chromatogram peak heights (unculibrated). The line represents the least squares linear regression of data points observed $(r=0.999)$. The negative slope of this line is the natural logarithm of the gas/blood partition coefficient plus one. The intercept on the $y$ axis is the natural logarithm of a value which when converted to isofurane vapour concentration and multiplied by barometric pressure is the tension of isoflurane in the original blood sample.

The natural logarithms of chromatogram peak heights from each of the four equilibrated gas phases were plotted in the order in which equilibrations were performed, to yield a graph relating log chromatogram peak height to numbered successive equilibrations (see Figure 1). If equilibration, separation and measurement techniques are exact and if the partition coefficient is independent of absolute tension, these plotted points should fall on a straight line with a negative slope. ${ }^{3}$ The negative slope of this line can be shown to be the logarithm of the gas/blood partition coefficient plus one, and the $y$ axis intercept - with appropriate calibration - the logarithm of a concentration of isoflurane which would have existed in a gas phase equilibrated with the original blood sample (see Appendix). Using the least squares technique, we found the regres- 
sion line of each set of equilibrated gas phase data, and from its slope and $y$ axis intercept, computed the blood/gas partition coefficient and the blood tension (Appendix). Results from duplicate samples were averaged.

We examined the results for possible differences in partition coefficient among patient groups classified according to type of surgical procedure. We checked for correlations between individual values of blood/gas partition coefficient and each of the following: isoflurane blood tension, preoperative haemoglobin concentration and patient age.

Effects of haemodilution and blood temperature on isoflurane solubility were examined in vitro. To study haemodilution, we withdrew blood from each of four unanaesthetized non-fasting volunteers and divided it into four syringes pre-wetted with heparin. To $5 \mathrm{ml}$ whole blood in one syringe, we added normal saline $1 \mathrm{ml}$; to $5 \mathrm{ml}$ in a second syringe, mannitol 20 per cent $1 \mathrm{ml}$; and to $5 \mathrm{ml}$ in a third syringe, stored plasma $1 \mathrm{ml}$. Six $\mathrm{ml}$ whole blood in a fourth syringe were left unchanged. To each syringe we then added air $4 \mathrm{ml}$ containing isoflurane approximately 2 per cent. The mixtures were equilibrated at $37^{\circ} \mathrm{C}$ (range $\pm 0.1^{\circ} \mathrm{C}$ ) and the gas phases were expelled. The blood/gas partition coefficients of isoflutane in the remaining blood phases were determined by the gas equilibration technique described above. To assess the effect of temperature, additional blood samples were taken from six patients anaesthetized with isoflurane and partition coefficients were found with equilibrations performed at $30^{\circ} \mathrm{C}$, at $37^{\circ} \mathrm{C}$ and at $40^{\circ} \mathrm{C}$ (range at each temperature $\pm 0.1^{\circ} \mathrm{C}$ ).

After a review of our results, we extended the study to examine the effect of mannitol on isoflurane solubility in vivo. From five additional neurosurgery patients who were anaesthetized with isoflurane, we withdrew samples of blood immediately before and two hours after administration of mannitol. In each patient, mannitol 20 per cent was infused over 30 minutes to a total dose of $1 \mathrm{gm} / \mathrm{kg}$. Blood/gas partition coefficients were determined as above.

To test for possible differences related to type of surgical procedure, we employed the Student's $t$ test for unpaired data. To check for correlations between individual values of partition coefficient and isoflurane blood tension, haemoglobin concentration and patient age, we used the least squares
TABLE Isoflurane blood tensions and blood/gas partition coefficients

\begin{tabular}{|c|c|c|c|}
\hline & $n$ & $\begin{array}{l}\text { Blood tensions } \\
\left(k^{P} a\right)\end{array}$ & Partition coefficients \\
\hline $\begin{array}{l}\text { Minor surgery* } \\
\text { patients }\end{array}$ & 23 & $\begin{array}{c}0.82 \pm 0.24 \\
(0.45-1.37)\end{array}$ & $\begin{array}{c}1.20 \pm 0.08 \\
(1.02-1.32)\end{array}$ \\
\hline $\begin{array}{l}\text { Neurosurgery } \dagger \\
\text { patients }\end{array}$ & 20 & $\begin{array}{c}0.83 \pm 0.36 \\
(0.32-1.50)\end{array}$ & $\begin{array}{r}1.14 \pm 0.09 \ddagger \\
(0.97-1.35)\end{array}$ \\
\hline
\end{tabular}

Values are means $\pm S . D$. (bracketed values are ranges).

*Patients undergoing gynaecological, orthopaedic, dental or ENT procedures of a minor nature.

†Patients undergoing clipping of a cerebral aneurysm or removal of brain tumour.

FSignificantly different from minor surgery patient values $(\mathrm{p}<0.05)$.

linear regression technique. To test for differences related to haemodilution, blood temperature and mannitol infusion, we used the Student's $t$ test for paired data.

\section{Results}

Correlation coefficients between log chromatogram peak heights, representing isoflurane concentrations of successive equilibrated gas phases, and equilibration number were all 0.995 or greater. Variability of partition coefficients determined in duplicate samples was \pm 2.8 per cent or less; variability of absolute tensions was \pm 4.1 per cent or less.

Isoflurane blood tensions and blood/gas partition coefficients are presented in the Table. Partition coefficients determined in samples from patients undergoing neurosurgical procedures were significantly less than those from patients undergoing minor surgical procedures $(p<0.05$ ). Results of these groups are presented separately.

Ranges of partition coefficient values are also presented in the Table. There were no significant correlations between individual values of partition coefficient and each of the following variables in the minor surgery group: isoflurane blood tension (range given in the Table), preoperative haemoglobin concentration (range $10.0-17.1 \mathrm{gm}$ per cent) and patient age (range 20-75 years). There were no significant correlations of partition coefficient with the same variables in the neurosurgery patient group (haemoglobin range $11.1-15.1 \mathrm{gm}$ per cent, age range $34-65$ years). 


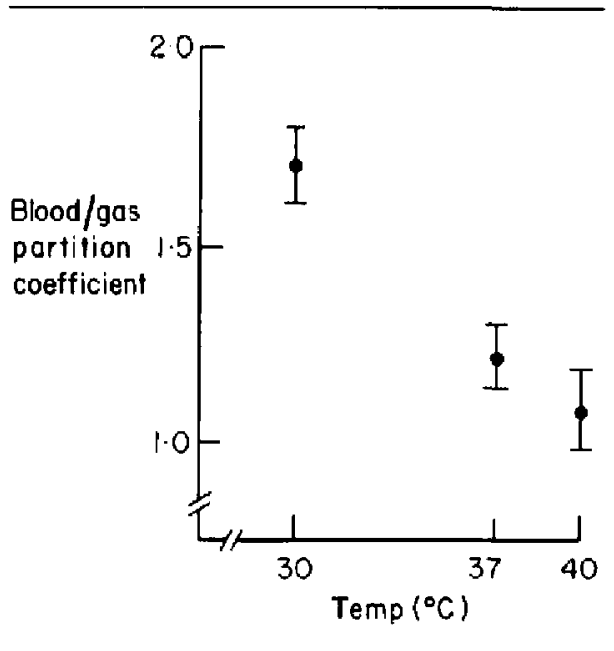

FIGURE 2 Effect of temperature on the blood/gas partition coefficient of isoflurane. Hypothermia increased and hyperthermia decreased the partition coefficient (means \pm S.D., $n=6$. $p<0.01$ ).

In blood drawn from unanaesthetized non-fasting volunteers and exposed to isoflurane vapour in vitro, the blood/gas partition coefficient was $1.36 \pm$ 0.09 (mean \pm S.D., $\mathrm{n}=4$ ). (The differences between this value and the coefficients of the anaesthetized patient groups did not achieve conventional statistical significance ( $\mathrm{p}$ values $<0.10$ )). In vitro haemodilution with saline, mannitol 20 per cent and stored plasma reduced the partition coefficient from $1.36 \pm 0.09$ to $1.23 \pm 0.02,1.19 \pm 0.02$ and $1.24 \pm 0.07$ respectively (all $p$ values $<0.05$ ).

Partition coefficients in patient blood determined at $30^{\circ} \mathrm{C}, 37^{\circ} \mathrm{C}$ and $40^{\circ} \mathrm{C}$ were respectively $1.71 \pm$ $0.10,1.20 \pm 0.08$ and $1.07 \pm 0.12$ (means \pm S.D. $\mathrm{n}=6$, all $\mathrm{p}$ values $<0.01$, Figure 2 )

In blood drawn from the additional group of neurosurgery patients before mannitol was infused, the blood/gas partition coefficient was $1.23 \pm 0.07$ (mean \pm S.D., $\mathrm{n}=5$ ). In blood taken two hours after mannitol, the partition coefficient was $1.11 \pm$ $0.04(\mathrm{p}<0.05)$.

\section{Discussion}

Our method of determining blood'gas partition coefficient and blood tension of halogenated anaesthetic is an adaptation of a method used in analytical chemistry. ${ }^{3}$ In principle, it is similar to the gas phase equilibration technique described by Fink and Morikawa. ${ }^{4}$ However, we equilibrate the blood sample with several gas phases and use volumes of gases that are equal to the volume of the sample of blood.

Blood containing the anaesthetic is equilibrated with four equal yolumes of humidified air in succession in a gas-tight syringe at $37^{\circ} \mathrm{C}$. (In practice, we have found four gas-phase equilibrations to be adequate.) The concentration of anaesthetic vapour in each of these equilibrated gas phases is measured by gas chromatography. Since the concentration in the second, third or fourth equilibrated gas phase is a constant fraction or proportion of the concentration in the preceding equilibrated gas phase, the decline of concentrations in successive phases follows a first order or exponential pattern. Thus, when the logarithms of anaesthetic vapour concentrations in equilibrated gas phases (or chromatogram peak heights representing concentrations in gas phases) are plotted as a function of equilibration number, a simple linear relationship is observed (as in Figure 1).

The fractional decline of vapour concentrations in successive equilibrated gas phases is determined by the blond'gas partition coefficient; the absolute concentration in any phase is the result of the original blood content, the partition coefficient and the equilibration number of that phase. Accordingly, both partition coefficient and original blood content can be derived from the relationship between anaesthetic concentration in equilibrated gas phases and equilibration number. If logarithms of anaesthetic concentration are used, the partition coefficient is found from the slope of this relationship and the blood content from the value of the $y$ axis intercept, together with the slope. Original blood tension is calculated directly from the value of the $y$ axis intercept (see Appendix).

There are several potential advantages to the use of this method. It yields solubility and tension from the same analytical procedure and it provides multiple data points to estimate each. In the absence of offsetting errors, goodness of fit of individual sets of data points to a regression line provides a sensitive check on the adequacy of equilibration, separation and measurement procedures. When used as described, this method does not require that there be any particular volume of blood and gas in the sample syringe; one must ensure only that blood 
and gas volumes are equal at the end of each equilibration. Finally, determination of the partition coefficient does not depend upon absolute calibration of the chromatograph, because the coefficient is calculated from the slope of logarithms of chromatogram values and the slope of logarithms of a set of values is unaffected by proportionate changes in these values. Thus, provided the response of the chromatograph to variation of anaesthetic concentration is linear, the partition coefficient can be derived directly from values of uncalibrated chromatogram peak heights (as are given in Figure 1).

The value of isoflurane blood/gas partition coefficient found in samples from our patients undergoing minor surgery was $1.20 \pm 0.08$ (mean \pm S.D.). This mean value is identical with that found by Munson et al. in venous blood taken from fasting volunteers and exposed to isoflurane 0.6 per cent in vitro, ${ }^{2}$ but somewhat less than the usually quoted value of 1.43 which was reported by Cromwell $e t$ al. ${ }^{1}$ Our estimates were based upon analyses of arterial blood exposed to anaesthetizing concentrations of isoflurane in vivo. That these estimates were accurate is supported by our findings of consistently high correlations between the log chromatogram peak heights of successive equilibrated gas phases and equilibration number, and good reproducibility of partition coefficients in duplicate samples. We are unable to account for the higher value reported by Cromwell et al.

Solubility of other volatile anaesthetics in human blood has been reported to be affected by many factors, including the absolute tension of the agent in the sample, haemoglobin concentration, blood temperature, serum proteins, lipid levels and recent feeding. ${ }^{2,5-13}$ In this study, there was no detectable relationship between the absolute tension of isoflurane and its solubility over the range of tensions originally present in our patients' blood samples. (Since individual values of partition coefficient were in fact determined over a wide range of isoflurane tensions consequent upon multiple gas phase extractions, one would expect an effect of tension on solubility to be evident in individual equilibrated gas phase results - specifically as a distortion of the linear relationships between $\log$ chromatogram peak heights and equilibration numbers. No consistent distortion of these relationships was evident.) There was no detectable relationship between indi- vidual isoflurane blood/gas partition coefficients and values of preoperative hacmoglobin concentration. However, preoperative haemoglobin concentrations may not have been identical with concentrations present in the blood samples in which partition coefficients were determined. Obviously, our failure to detect relationships between solubility and these factors does not exclude their existence.

Haemodilution of whole blood with normal saline, mannitol 20 per cent or stored plasma in vitro (one part diluent added to five parts blood) reduced values of isofurane blood/gas partition coefficient. It is known that other volatile anaesthetics tend to be less soluble in saline and plasma than in blood. ${ }^{7-9,11}$ That haemodilution with these solutions reduced isoflurane solubility is therefore not surprising. A reduced blood temperature $\left(30^{\circ} \mathrm{C}\right)$ increased isoflurane solubility and an increased temperature $\left(40^{\circ} \mathrm{C}\right)$ decreased it, each by relative magnitudes similar to those observed with other volatile agents. ${ }^{9}$ Solubility tended to be greater in blood drawn from our non-fasted awake volunteers than in blood drawn from fasted anaesthetized patients $(1.36 \pm 0.09$ and $1.20 \pm 0.08$ respectively, $p<0.10)-$ perhaps due to an effect of recent feeding on solubility. ${ }^{2}$

The partition coefficient detcrmined in blood taken from our main group of patients undergoing neurosurgical procedures was slightly less than that observed in blood from patients undergoing minor surgery $(1.14 \pm 0.09$ and $1.20 \pm 0.08$ respectively). Neurosurgery patients differed from the others in that all had received a mannitol infusion $(1 \mathrm{gm} /$ $\mathrm{kg}) 45$ minutes to four hours prior to the time of sampling blood. We attribute the reduced solubility observed in these patients to the effects of mannitol because (1) diluting whole blood in vitro with mannitol decreased the partition coefficient and (2) infusing mannitol $(1 \mathrm{gm} / \mathrm{kg})$ into another group of neurosurgery patients decreased the partition coefficient two hours after infusion by a magnitude sufficient to account for the original observation.

The mean value of the blood/gas partition coefficient for halothane is reported to be 2.3 to $2.5 .^{9,11,13.14 *}$ The mean value for isoflurane, ac-

*Using the multiple gas phase equilibration method as described in this report, we found the blood/gas partition coefficient for halothane to be $2.35 \pm 0.08$ (mean $\pm S$. D., $\mathrm{n}=18$, unpublished observations). 
cording to Munson's study and our study, is 1.2. We conclude that the solubility of isoflurane in human blood is about half that of halothane.

\section{Acknowledgements}

The authors wish to acknowledge the assistance of Miss J. Clement in the analysis of data and of Mrs. L. Nolan in the preparation of this report. We also wish to thank Dr. J. Roberts of the Flinders University of South Australia for his helpful criticisms of the manuscript.

\section{References}

1 Cromwell TH, Eger EI, Stevens WC, Dolan WM Forane uptake, excretion, and blood solubility in man. Anesthesiology 1971: 35: 401-8.

2 Munson ES, Eger EI. Tham MK, Embro WJ Increase in anesthetic uptake, excretion, and blood solubility in man after eating. Anesth Analg 1978; 57: 224-31.

3 McAuliffe C. G C determination of solutes by multiple phase equilibration. Chem Tech 1971; Jan: 46-51.

4 Fink BR, Morikawa $K$. A simplified method for the mcasurement of volatile anesthetics in blood by gas chromatography. Anesthesiology 1970; 32: $451-5$.

5 Lowe HJ, Hagler $K$. Determination of volatile organic anesthetics in blood, gases, tissues and lipids: partition coefficients. In: Gas Chromatography in Biology and Medicine. Ed. Ruth Porter. London: J. \& A. Churchill, Ltd (1969).

6 Cowles $A L$, Borgstedt $H H$, Gillies $A$, . Solubilities of ethylene, cyclopropane, halothane and diethyl ether in human and dog blood at low concentrations. Anesthesiology 1971; 35: 203-11.

7 Gregory GA, Eger EI. Partition coefficients in blood and blood fractions at various concentrations of cyclopropane. Fed Proc 1968; 27: 705.

8 Robbins BH. Studies of cyctopropane I. The quantitative determinations of cyclopropane in air, water, and blood by means of iodine pentoxide. J Pharmacol Exp Ther 1936; 58: 243-7.

9 Stoelting $R K$, Longshore $R K$. The effects of temperature on fluroxene, halothane, and methoxyflurane blood-gas and cerebrospinal fluid-gas partition coefficients. Anesthesiology 1972; 36: 503-5.

10 Saidman LJ, Eger EI, Munson ES, Severinghaus $J W$. A method for determining solubility of anes- thetics utilizing the Scholander apparatus. Anesthesiology 1966; 27 : 180-4

11 Laasberg $W$, Hedley-Whyte J. Halothane solubility in blood and solutions of plasma proteins. Anesthesiology 1970; 32: 351-6.

12 Saraiva RA, Willis BA, Steward A et al. Halothane solubility in human blood. Br J Anaesth 1977; 49: 115-9.

13 Wagner $P D$, Naumann $P F$, Laravuso RB. Simultaneous measurement of eight forejgn gases in blood by gas chromatography. J Appl Physiol 1974; 36: $600-5$.

14 Larson CP, Eger II EI, Severinghaus JW. The solubility of halothane in blood and tissue homogenates. Anesthesiology 1962; 23: 349-55.

\section{Résumé}

En utilisant plusieurs techniques d'équilibration des gaz, on a déterminé la solubilité de l'isoflurane $a 37^{\circ} \mathrm{C}$ avec des echantillons de sang abtenus chez des patients anesthésiés au moyen de concentrations d'isoflurane. Le fait que les résultats obtenus concordent avec ceux prédits ainsi que la reproductibilité de ces résultats indiquent que la technique analytique est acceptable. Des échantillons de sang obtenus de 23 patients prépares pour intervention chirurgicale, le coefficient-partition des gaz du sang de l'isofurane était de $1.20 \pm 0.08$ (moyenne $\pm S . D$. .). Les valeurs individuelles $n^{*}$ etaient pas reliées de façon détectable à la tension absolue de l'isofiurane ni a la concentration en hémoglobine préopératoire. Les échantillons obtenus de 20 patients préparés pour intervention chirurgicale en neurochirurgie ont démontré que le coefficient des gaz du sang etait sensiblement plus bas, $1.14 \pm 0.09$ ( $p<0.05)$. Cette différence est attribuée à l'effet du mannitol infusé au préalable. La solubilité de l'isofurane in vitro fut réduite par l'hémodilution avec la solution salée (normale), 20 pour cent de mannitol ou de plasma, augmentée par l' hypothermie $\left(30^{\circ} \mathrm{C}\right)$ et diminuée par l' hyperthermie $\left(40^{\circ} \mathrm{C}\right)$. Nous conchons donc que la solubilite de $l$ 'isofitrane dans le sang humain est approximativement la moitie de celle de l'halothane.

\section{Appendix}

Determination of blood/gas partition coefficient and blood tension from multiple gas phase equilibration.

Consider the distribution of volatile anaesthetic between a sample of blood containing the anaes- 
thetic and multiple gas phases of equal volume with which the blood sample is equilibrated in succession (as outlined in Methods).

Let

$X_{O}=$ total quantity of anaesthetic in original blood sample before equilibrations.

$P_{o}=$ tension of anaesthetic in original blood sample.

$X_{i}=$ total quantity of anaesthetic in blood and gas phases together at equilibration $i$.

$G_{i}=$ quantity of anaesthetic in gas phase at equilibration $i$

$B_{i}=$ quantity of anaesthetic in blood phase at equilibration $i$.

$\lambda_{G}=$ gas/blood partition coefficient of anaesthetic.

$\lambda_{B}=$ blood/gas partition coefficient of anaesthetic.

$n \quad=$ equilibration number

$P_{\text {bar }}=$ barometric pressure

In the special case where equilibrated blood and gas volumes are equal

(I) $\lambda_{G}=\frac{G_{i}}{B_{i}}$

but

(2) $B_{i}=X_{i}-G_{i}$

Substituting (2) into (1) and rearranging

(3) $G_{i}=\frac{\lambda_{G} X_{i}}{\lambda_{G}+1}$

Similarly

(4) $B_{i}=\frac{X_{i}}{\lambda_{G}+1}$

In the case of equilibration $i+1$, total quantity of anaesthetic in blood and gas phases equals the quantity in blood at equilibration $i$, i.e.

(5) $X_{i+1}=B_{i}=\frac{X_{i}}{\lambda_{G}+1}$

Therefore, from equations (3) and (5)

(6) $G_{i+1}=\frac{\lambda_{G} X_{i}}{\left(\lambda_{G}+1\right)^{2}}$
Generalizing equation (6)

(7) $G_{n}=\frac{\lambda_{G} X_{o}}{\left(\lambda_{G}+1\right)^{n}}$

or

(8) $\log G_{n}=-\left[\log \left(\lambda_{G}+1\right)\right] n+\log \lambda_{G} X_{O}$

Equation (8) is in the form of the equation of a line, $y=a x+b$, in which

$$
\begin{aligned}
& y=\log G_{n} \\
& x=n
\end{aligned}
$$$$
\text { (9) } a=-\log \left(\lambda_{G}+1\right)
$$$$
\text { (10) } b=\log \lambda_{G} X_{O}
$$

Thus, plotting $\log G_{n}$ as a function of $n$ should yield a linear relationship (as in Figure 1), the negative slope of which is $\log \left(\lambda_{G}+1\right)$ and the intercept $\log \lambda_{G} X_{O}$.

Blood/gas partition coefficient is calculated from the negative slope ( $-a)$. Rearranging equation (9)

$\lambda_{G}=\operatorname{antilog}(-a)-1$

and therefore

$\lambda_{B}=\frac{1}{\operatorname{antilog}(-a)-1}$

Blood tension is calculated from the intercept $(b)$ which is the logarithm of the product of the gas/blood partition coefficient and the original blood content, and thus represents the quantity of anaesthetic in a mythical gas phase in equilibrium with the original blood sample. When $b$ is expressed as the logarithm of a vapour concentration $P_{O}=\operatorname{antilog} b P_{\mathrm{bar}}$

When multiple equilibrations are performed, goodness of fit of data points to a linear relationship acts as a check on the independence of anaesthetic solubility from anaesthetic tension and the exactness of each step of the equilibration, separation and measurement procedures. 